\title{
HISTÓRIA E MEMÓRIA: EXPANSÃO DO CAMPUS UNIVERSITÁRIO DE ABAETETUBA
}

\author{
Ladyana dos Santos LOBATO \\ Campus Universitário de Abaetetuba \\ ladyanas1@ufpa.br \\ Dedival Brandão da SILVA \\ FAECS/Campus Universitário de Abaetetuba \\ dedivalbs@ufpa.br
}

Resumo: Discorremos, no presente artigo, sobre a história e a memória do Campus Universitário de Abaetetuba, objetivando enfatizar alguns momentos da expansão física do Campus e as implicações dessas mudanças na vida dos sujeitos envolvidos. Para isso, utilizamos como instrumentos de análise imagens fotográficas selecionadas do acervo fotográfico do Campus e alguns registros históricos. Utilizamos como referencial teórico os estudos sobre Memória desenvolvidos por Le Goff (1990). Partindo desse referencial, compreendemos o uso da fotografia enquanto instrumento de guarda e preservação da memória e a necessidade do registro da história da Instituição para a preservação de sua identidade e conhecimento às novas gerações.

Palavras-chave: Campus Universitário de Abaetetuba. História. Memória. Expansão física. Fotografia.

Abstract: We discourse, in this article about the history and memory of Campus Abaetetuba, aiming to emphasize a few moments of physical expansion of the Campus and the implications of changes in the lives of the individuals involved. For this, we use as analytical tools images selected from the photographic collection of the campus and some historical records. We use as theoretical studies of memory developed by Le Goff (1990). Considering this, we understand the use of photography as a means of guarding and preserving the memory and the need to record the history of the institution to preserve its identity and knowledge to new generations.

Keywords: Campus Abaetetuba. History. Memory. Physical expansion. Photography. 


\section{Introdução}

Os avanços científicos e tecnológicos que eclodiram no final do século XIX e início do século XX criaram artefatos culturais que influenciaram significativamente o modo de vida das pessoas. Entre esses artefatos culturais encontramos a fotografia, instrumento que, acompanhando a rapidez da vida moderna, aperfeiçoou-se ao longo do tempo e constituiu-se em um recurso importante para o registro e a preservação da memória.

De acordo com Eberhardt (2011), a fotografia, no início do século $\mathrm{XX}$, encontrou espaço dentro dos grupos familiares. Constituía os chamados "álbuns de família" e era usada por estes grupos para preservar seus costumes, fortalecer a união dos indivíduos e sua identidade. No entanto, os hábitos de criação e preservação de álbuns foram transferidos a outros setores da sociedade, entre eles, as instituições educacionais. É assim que, atualmente, a construção de álbuns fotográficos institucionais é uma tarefa comum em algumas entidades, sendo uma forma utilizada para registrar o cotidiano destes órgãos, seus momentos especiais e, mais especificamente, suas transformações, o que não deixa de ser um exercício de preservação da memória institucional.

Sob esta perspectiva, é que nos propomos, neste artigo, analisar a imagem fotográfica enquanto objeto material de registro e constituição da história do Campus Universitário de Abaetetuba. As imagens selecionadas expressam indícios de uma realidade que contribui para a preservação do passado e a compreensão das mudanças históricas que acompanham os mais de 20 (vinte) anos do Campus no Município de Abaetetuba, em sua sede atual. É uma retomada à memória histórica que precisa ser divulgada às novas gerações (docentes, técnicos, alunos, bolsistas, servidores terceirizados e municipais), isto é, a todos aqueles que atualmente são sujeitos deste processo, mas desconhecem sua história.

No entanto, um aspecto importante a ser destacado quando falamos de memória é a sua relação com os lugares. Tendo isso em vista, restringimo-nos, neste artigo, ao estudo do "lugar", enquanto referência para a construção da memória individual e coletiva. Objetivamos, assim, registrar a história do Campus Universitário de Abaetetuba, enquanto instituição espacialmente localizada à Rua Manoel de Abreu, sem número, 
Bairro do Mutirão, ressaltando sua expansão física e as implicações dessas mudanças na vida dos sujeitos. Restringimos nosso estudo à expansão do Campus de Abaetetuba porque compreendemos que as mudanças espaciais implicam efetivamente na memória dos grupos. E aqui, não vemos o "lugar" enquanto um espaço territorial notadamente demarcado geograficamente, mas um espaço simbólico, de representação e de práxis pedagógica. Evidenciar as mudanças ocorridas neste "lugar" será fundamental para compreender suas implicações na vida e na memória dos seus sujeitos. Isto porque:

As memórias dos grupos se referenciam, também, nos espaços em que habitam e nas relações que constroem com estes espaços. Os lugares são importantes referência na memória dos indivíduos donde se segue que as mudanças empreendidas nesses lugares acarretam mudanças importantes na vida e na memória dos grupos (KESSEL, 2011, p. 4).

Esta busca contribuirá com os registros já existentes que, com o mesmo objetivo, buscam preservar a memória do Campus, no entanto, neste artigo, apontamos para uma concepção de história, na qual esta não é uma ciência do passado, mas uma "ciência da mutação e da explicação dessa mudança” (LE GOFF, 1990, p.15). É esta concepção de História que responde às nossas expectativas neste artigo, no qual buscamos resgatar a História do Campus Universitário de Abaetetuba, partindo de uma memória coletiva. Sob essa concepção, compreenderemos que a História do Campus de Abaetetuba não é uma História de um tempo passado, iniciado e estático há 20 (vinte) anos atrás, mas uma História de mudanças, de expansão, que vem acompanhando as modificações sociais e a influência de seus sujeitos. Esse breve resgate se deve ao fato de que "a memória é um elemento essencial do que se costuma chamar identidade, individual ou coletiva, cuja busca é uma das atividades fundamentais dos indivíduos e das sociedades de hoje, na febre e na angústia" (LE GOFF, 1990, p. 476).

Para auxiliar-nos, neste trabalho, recorreremos à base teórica contida em Le Goff (1990), no que concerne a seus estudos sobre Memória. Em seguida, analisaremos as imagens fotográficas selecionadas, descrevendo-as, ressaltando suas principais evidências de expansão 
física do Campus Universitário de Abaetetuba e as implicações dessas mudanças na vida de seus sujeitos. Finalizaremos este artigo, levando em consideração o uso da fotografia, enquanto instrumento de guarda e preservação da memória e a necessidade do registro da história da instituição para a preservação de sua identidade e conhecimento às novas gerações.

\section{Memória e Fotografia}

O conceito de memória e a forma como esta funciona vem sendo tema de estudos desde os tempos mais remotos. Em cada época, a forma de lidar com esse estudo se contextualizou segundo uma concepção científica e filosófica estritamente relacionada ao contexto histórico e social ao qual estava inserida.

Kessel (2011) ajuda-nos a fazer um breve recorte da concepção e do uso da memória em determinados períodos históricos. Segundo esta autora, para os antigos gregos a memória era sobrenatural, pois era uma deusa, de nome Mnemosine, mãe das musas, a qual possibilitava aos poetas lembrar dos grandes feitos dos heróis e transmiti-los aos mortais. Já para os romanos, de acordo com esta autora, a memória era um instrumento importante à arte retórica, pois o orador, para convencer e emocionar seus ouvintes, deveria recorrer à memória e não aos registros escritos. No período medieval, de acordo com Kessel (2011), a memória foi utilizada para recorrer a uma memória litúrgica, por meio da qual os acontecimentos e milagres do passado lembravam os santos católicos.

$\mathrm{Na}$ atualidade, de acordo com Kessel (2011), com a urbanização, os avanços tecnológicos e o dinamismo das relações sociais, aconteceram mudanças importantes para a concepção e o uso da memória individual e coletiva. Segundo a autora, desenvolveram-se "artifícios cada vez mais sofisticados para guardar e disseminar a memória em textos e imagens." É entre estes artifícios que apontamos, mais especificamente neste artigo, a fotografia enquanto instrumento que eterniza um momento, em dado espaço e tempo histórico, e constrói a memória e a identidade das pessoas, dos lugares e dos eventos. Ao preservar a memória, "o retrato fotográfico se coloca como uma prova material da existência humana, 
além de alimentar a memória individual e coletiva de homens públicos e de grupos sociais" (BORGES apud EBERHARDT, 2011, p. 3).

Assim, ao representar o passado, as fotografias transmitem ao seu observador um recorte de uma realidade passada, a qual em face da realidade presente, denota para a constituição da história dos grupos sociais, pois a "medida em que identificadas e analisadas objetiva e sistematicamente com base em metodologias adequadas, se constituirão em fontes insubstituíveis para a reconstituição histórica dos cenários, das memórias de vida" (KOSSOY apud EBERHARDT, 2011, p. 3). Isso significa que a fotografia exerce papel fundamental para a transmissão, aos mais jovens, dos saberes, conhecimentos, artefatos culturais, modos de vida do passado, entre outros.

O retrato fotográfico, ao constitui-se em um objeto material, carrega consigo informações mais valiosas do que sua própria constituição material. O que queremos dizer é que o real valor do suporte material da fotografia não está em sua forma, mas em seu conteúdo, isto é, na imagem que ela foi capaz de captar, o que ela representa e os discursos que expressa. Existe na fotografia um conteúdo imaterial que é simbólico e que, por isso, é capaz de provocar sensações universais, mas também individuais em cada indivíduo que a observa. Essas sensações estão estritamente relacionadas à noção de memória do ser humano, pois é a partir dela que "a imagem que se analisa passa a possuir significado no momento que aciona a imaginação individual e, portanto, constrói uma representação" (EBERHARDT, 2011, p. 4).

Nesse sentido:

A imagem é o relê que aciona nossa imaginação para dentro de um mundo representado (tangivel ou intangivel), fixo na sua condição documental, porém moldável de acordo com nossas imagens mentais, nossas fantasias e ambições, nossos conhecimentos, nossas realidades e nossas ficções. A imagem fotográfica ultrapassa, na mente do receptor, o fato que representa (KOSSOY apud EBERHARDT, 2011, p. 4).

Percebemos, portanto, que a fotografia, por meio de um processo psíquico que atravessa o olhar sobre ela, aciona um processo mais complexo que é o de memória individual e, portanto, de memória coletiva.

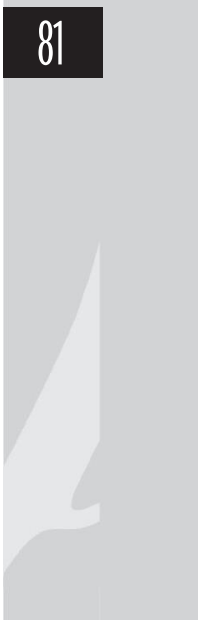


As sociedades modernas em busca de manutenção, guardam, registram e preservam sua memória, em especial, a partir do século XX, e dentre outros instrumentos, utilizam a fotografia que "revoluciona a memória: multiplica-a e democratiza-a, dá-lhe uma precisão e uma verdade visuais nunca antes atingidas, permitindo assim guardar a memória do tempo e da evolução cronológica" (LE GOFF, 1990, p. 466). Isso significa que a imagem expressa na fotografia revela-se além do que nossos olhos são capazes de contemplar, ou seja, quando apreciamos uma fotografia, nosso imaginário busca um referente, um significado, um discurso que remota nossas imagens mentais, isto porque "fotografia é memória e com ela se confunde" (KOSSOY apud EBERHARDT, 2011, p. 5).

Memória para Moreira (2011):

no sentido primeiro da expressão, é a presença do passado. A memória é uma construção psíquica e intelectual que acarreta de fato uma representação seletiva do passado, que nunca é somente aquela do indivíduo, mas de um indivíduo inserido num contexto familiar, social, nacional (MOREIRA, 2011, p.1).

Esta definição nos remete para uma concepção bastante filosófica de memória, na qual esta compreende a capacidade que temos de guardar informações, experiências, conhecimentos, de forma mental e em determinados momentos, evidenciar essas informações passadas, no tempo presente. Atualmente, as ciências que vêm fazendo estudos sistemáticos sobre a memória percebem a necessidade de aproximá-la das ciências humanas, isto porque, têm-se percebido a relação existente entre a memória e o que Le Goff (1990) chama de "sistemas dinâmicos de organização". A linguagem, por exemplo, é para Le Goff (1990), um destes sistemas, por meio do qual a memória vem se consolidando, pois tem se observado, de acordo com este autor, que antes da expressão de uma ideia, seja falada ou escrita, esta já estava armazenada na memória. Além disso, alguns pesquisadores da memória:

observaram que os sentimentos inerentes ao homem, como o desejo, a afetividade, a censura, podem manipular a memória individual, consciente ou inconscientemente. Em relação à memória coletiva, observaram que esta pode ser 
manipulada pelos grupos que objetivam exercer o poder em determinados momentos históricos (SILVA; LIMA, 2003, p. 9789).

Historicamente, a memória vem sendo influenciada por profundas modificações. A passagem da memória pela oralidade ao aparecimento da escrita trouxe inovações cruciais na forma de registrar e reordenar a memória coletiva dos grupos sociais. Segundo Le Goff (1990), esse desenvolvimento acompanhou o crescimento dos centros urbanos, os avanços tecnológicos e as exigências advindas da vida do homem em sociedade. A imprensa exerceu papel fundamental neste processo, pois revolucionou a memória ocidental trazendo à tona, entre outros, a necessidade de registrar a memória por meio da construção de monumentos, abertura de museus e, em especial, das fotografias. Neste contexto "a memória eletrônica não é senão um elemento, sem dúvida o mais espetacular” (LE GOFF, 1990, p. 467).

Em suma: Memória individual e coletiva se alimentam e têm pontos
de contato com a memória histórica e, tal como ela, são
socialmente negociadas. Guardam informações relevantes
para os sujeitos e têm, por função primordial garantir a
coesão do grupo e o sentimento de pertinência entre seus
membros. Abarcam perídos menores do que aqueles tratados
pela história. Têm na oralidade o seu veículo privilegiado,
porém não necessariamente exclusivo, de troca. Já a memória
histórica tem no registro escrito um meio fundamental de
preservação e comunicação. Memória individual, coletiva
e histórica se interpenetram e se contaminam. Memórias
individuais e coletivas vivem num permanente embate pela
co-existência e também pelo "status" de se constituírem como
memória histórica (KESSEL, 2011, p. 5.)

Assim, o estudo sobre a memória faz-se crucial para compreender a história, pois sem ela e seu registro não haveria formas concretas de se contar, escrever, avaliar e reavaliar a história dos homens. Isto porque a "memória, onde cresce a história, que por sua vez a alimenta, procura salvar o passado para servir o presente e o futuro. Devemos trabalhar de forma a que a memória coletiva sirva para a libertação e não para a servidão dos homens.” (LE GOFF, 1990, p. 477). 


\section{Registros Fotográficos, História e Memória do Campus Universitário de Abaetetuba}

Analisaremos, a partir de agora, aspectos memorialísticos do Campus Universitário de Abaetetuba, a partir de imagens fotográficas, evidenciando as mudanças históricas de expansão física do Campus e sua influência na vida dos sujeitos.

De acordo com a Universidade Multicampi (2011), o Campus Universitário de Abaetetuba, foi implantado em 1987, no município de Abaetetuba, sob a coordenação da professora Conceição Solano, indicada a esse cargo pelo reitor da época, o Prof. José Seixas Lourenço. Os primeiros cursos ofertados, Matemática, Letras, Pedagogia, História e Geografia, eram todos em regime intervalar e aconteciam nos espaços físicos do Colégio São Francisco Xavier, da Escola Estadual Prof. Basílio de Carvalho e da Escola Municipal Joaquim Mendes Contente, haja vista o Campus não tinha prédio próprio. Os espaços físicos destas escolas eram cedidos pela Prefeitura do Município que, além disso, era responsável pelo aluguel de casas onde funcionavam os alojamentos dos professores e a administração do Campus. Quanto a pessoal, a Prefeitura cedia servidores municipais para apoio administrativo, vigilantes e motoristas. Neste contexto, a Prefeitura do Município cedeu, também, as terras onde foi construído o Campus Universitário de Abaetetuba, há mais de 20 (vinte) anos.

Segundo a Universidade Multicampi (2011), a primeira coordenadora do Campus, professora Conceição Solano, esteve no cargo de 1987 a 1991. Em seguida, assumiu a coordenação o professor José Carneiro Queiroz, que exerceu dois mandatos, o primeiro de 1992 a 1995, por indicação; e o segundo de 1996 a 1999, por meio de eleição. Em 1999, também por eleição, o professor Adelino Ferranti assumiu a Coordenação do Campus, mandato de 2000 a 2004. A professora Francisca Maria Carvalho assumiu em 2006, após a coordenação do professor Waldir Abreu. Atualmente, o Campus Universitário de Abaetetuba é coordenado pelo Professor Eliomar Azevedo do Carmo, com a Vice-Coordenação da Professora Lina Gláucia Dantas Elias, eleitos para o interstício 2011-2014. 
Após este levantamento histórico, pesquisado em registros já existentes sobre a história do Campus de Abaetetuba, para a efetivação deste trabalho recorremos à Coordenação do Campus de Abaetetuba, que nos disponibilizou um acervo fotográfico que registra e guarda a história e a memória da expansão física do Campus de Abaetetuba. Para iniciar esta análise, achamos interessante evidenciar as imagens fotográficas abaixo, que apontam para o cartão-postal do Campus:

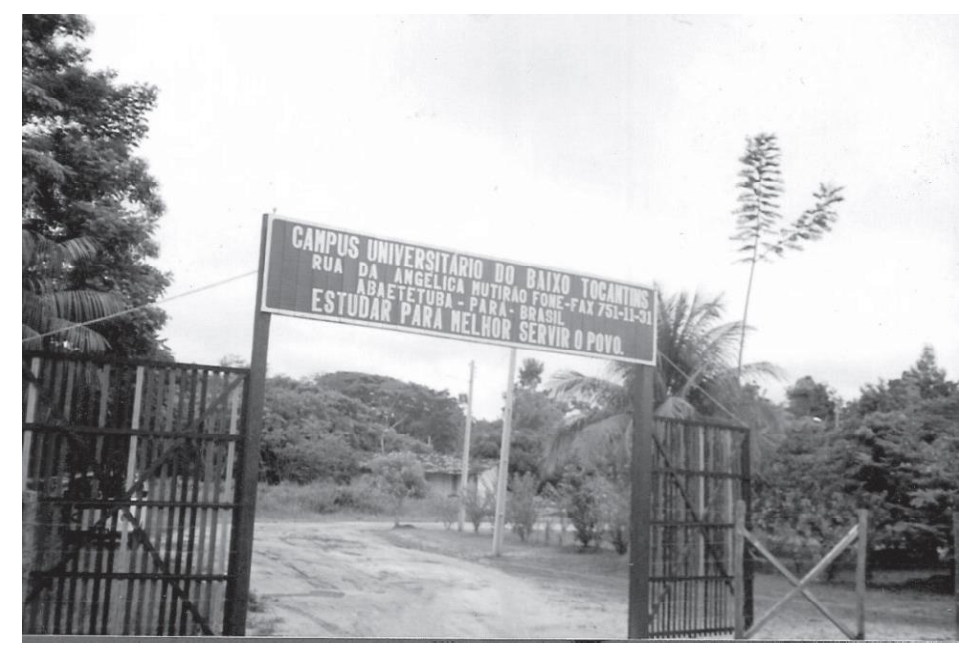

Fotografia 01 - Portão de acesso ao Campus.

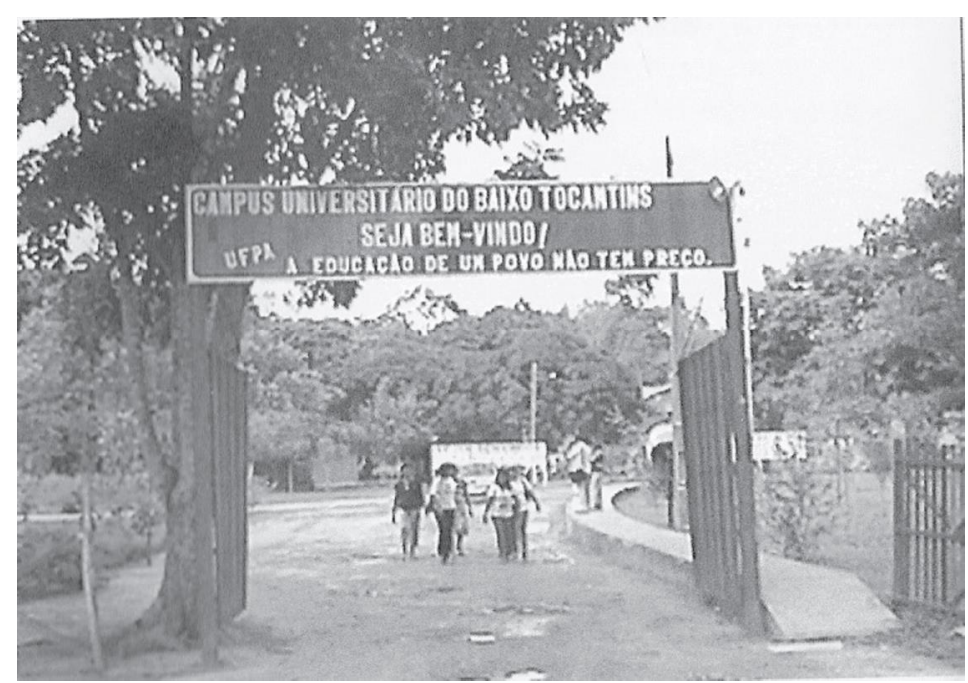

Fotografia 02 - Portão de acesso ao Campus. 
As fotografias selecionadas registram a imagem do portão de acesso ao Campus em dois períodos diferentes. Ambas constituemse em documentos impressos, encontram-se fixadas a um papel A4, junto a outras fotografias do Campus (algumas soltas, outras em álbuns fotográficos) dentro de um caixa arquivo de papelão, na Coordenação do Campus. As fotografias não apresentam referência quanto a data do registro, a pessoa que a tirou, o motivo e o contexto. Mas apontam para o desejo de registrar e preservar um momento histórico em que o Campus estava inserido.

As imagens fazem sentido, para este artigo, quando comparadas e não estudadas isoladamente. De certo, quando vistas isoladamente apontam para sentimentos universais, mais também individualizados. No entanto, quando vistas de forma articuladas apontam para uma história de transformações, na qual é possível acompanhar as ações de seus sujeitos. As imagens, entre o olhar de uma a outra, evidenciam a memória coletiva de um mesmo grupo, um sentimento de pertencimento, um retorno ao passado, para quem vivenciou ambos momentos; e um conhecimento deste passado, para quem não o conhecia. A memória coletiva tem

"uma importante função de contribuir para o sentimento de
pertinência a um grupo de passado comum, que compartilha
memórias. Ela garante o sentimento de identidade do
indivíduo calcado em uma memória compartilhada não
só no campo histórico, do real, mas sobretudo no campo
simbólico" (KESSEL, 2011, p. 3).

É neste campo simbólico que encontramos a representação das imagens na memória daqueles que a podem observar. $\mathrm{Na}$ primeira imagem, um motivo campestre caracteriza o cartão-postal da Instituição. Dentro do Campus, muitas árvores, possíveis de serem observadas, apontam para a falta de ocupação do espaço físico. As vias internas, lamaçadas, trazem uma certa umidade à imagem. O portão de madeira e os cercados nas cores azul, vermelho e amarelo denotam para a falta de estrutura física, ao mesmo tempo que fazem do espaço um lugar de tranquilidade e harmonia. No alto do portão, junto à identificação do lugar e o seu endereço, a frase: "Estudar para melhor servir o povo". Seria esta a filosofia do Campus para aquela época? Ainda é a mesma? Quais foram as mudanças? 
A fotografia 02, tirada anos depois da fotografia 01, guarda em seu registro mudanças visíveis de expansão do Campus de Abaetetuba, ao mesmo tempo em que preserva motivos da primeira fotografia. Ainda é possível observar o portão de madeira, desta vez, com uma madeira mais velha e sem a pintura. Uma árvore, de grande porte, do lado esquerdo de quem observa a fotografia, também registra uma grande mudança. Na placa de entrada já não consta a mesma frase. Desta vez, a frase "A educação de um povo não tem preço", a substitui. A via de acesso ao Campus não mudou, no entanto, do lado direito de quem observa a foto, é possível o registro de uma passarela. Além da passarela, um telefone público dentro do Campus e a breve vista de outros espaços construídos, apontam-nos para sua expansão. Outro fato notadamente importante chamou-nos a atenção na segunda fotografia: a presença de algumas pessoas, provavelmente alunos/as do Campus. Deste fato podemos inferir sobre a expansão de Cursos no Campus, os quais ampliaram o número de alunos e, consequentemente, influenciaram o cotidiano do Campus Universitário de Abaetetuba.

As imagens selecionadas registram uma memória que iniciou com a inauguração do Campus de Abaetetuba, no bairro do Mutirão, na Rua Manuel de Abreu, s/n, em 05 de janeiro de 1991. Uma época em que o Campus era formado por dois blocos, onde funcionavam a Secretaria, a Biblioteca, a cantina, o mimeógrafo e a Coordenação do Campus. De acordo com a Universidade Multicampi (2011), a expansão dos Cursos começou a partir de 1992, quando o Campus iniciou suas primeiras turmas dos cursos regulares de Letras e Matemática; prosseguiu a partir do ano 2000, com a oferta dos Cursos de Letras e Pedagogia em ToméAçu, Concórdia do Pará, Tailândia e mesmo em Abaetetuba, os quais foram regidos por contrato das prefeituras e subsidiados com recursos do Fundo de Desenvolvimento - FUNDEF. De acordo com a Universidade Multicampi (2011), em 2005 foram ofertadas, de forma flexibilizada (do Campus do Guamá), turmas dos cursos de Ciências Contábeis e Física. No ano de 2007, o Campus já ofertava 13 cursos com 1000 alunos matriculados.

Deste período, até os dias de hoje, outros registros guardam a memória do Campus, entre eles destacamos:

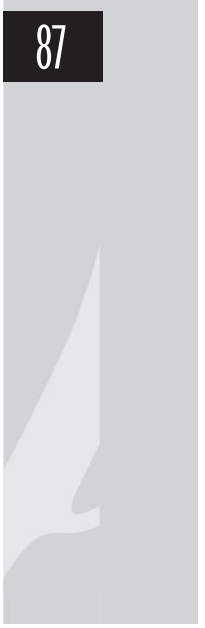




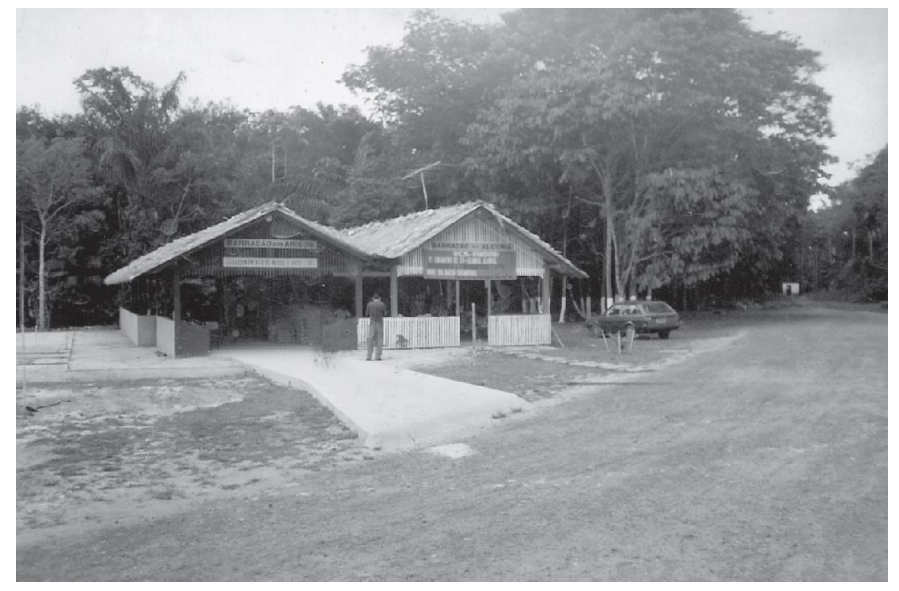

Fotografia 03 - "Barracão dos Amigos" e "Barracão da Alegria".

A fotografia 03 registra os espaços denominados de "Barracão dos Amigos" e "Barracão da Alegria". Ambos os espaços físicos, anexos um ao outro e construídos de madeira, representavam há alguns anos, um espaço de atividades de ensino, pesquisa e extensão, além de um espaço artístico-cultural e de encontro e eventos diversos. Na fotografia é possível observar a via de acesso ao Campus, de terra, e o pouco fluxo de pessoas. Este espaço, hoje, foi substituído pelo "Espaço Cultural "TocaTocantins":

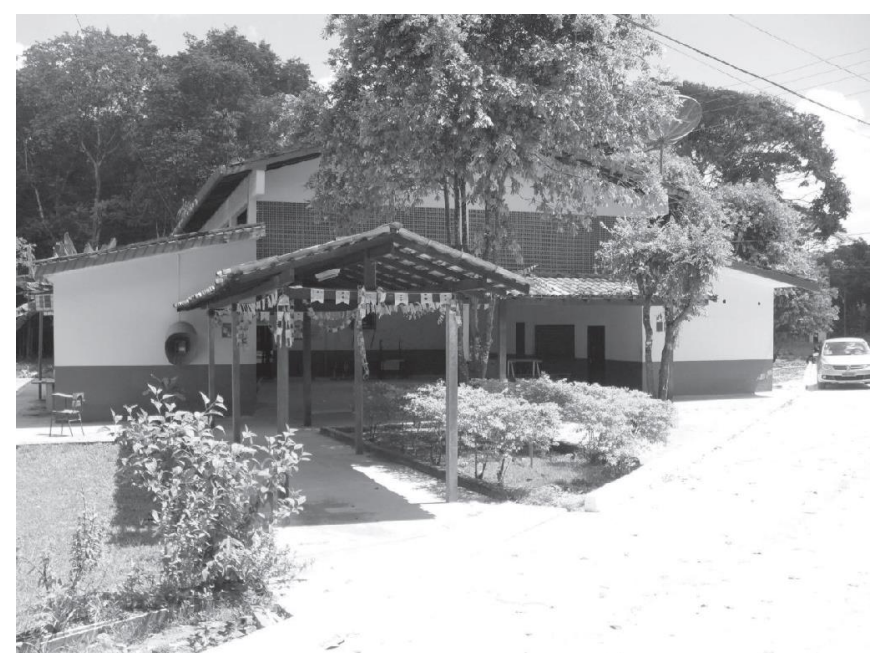

Fotografia 04 - Espaço Cultural "Toca-Tocantins". 
Com a mesma funcionalidade, o espaço "Toca-Tocantins", inaugurado em 2003, abriga a maioria das atividades acadêmico-culturais do Campus de Abaetetuba. Percebemos que os barracões de madeira foram substituídos por uma construção de alvenaria que anexa, ainda, o antigo "Auditório Cabanagem", hoje, substituído por um Auditório para 200 (duzentas) pessoas que se localiza em outro espaço físico do Campus, o qual comporta, também, a Biblioteca da Instituição. O que será do "Auditório Cabanagem"? O que será pensado para o espaço "Toca-Tocantins"? Muito além desta discussão, vale ressaltar que não é conveniente para a história do Campus deixar de guardar a memória de conquista deste espaço, o qual foi denominado "Toca-Tocantins" e "Auditório Cabanagem" por escolha da comunidade acadêmica em uma eleição.

No espaço registrado na fotografia 04 , guarda-se uma memória que, por algum tempo, movimentou toda a vida acadêmico-administrativa do Campus. Neste espaço, funcionaram os seguintes departamentos: Coordenação e Vice-Coordenação do Campus; Secretaria Executiva; Secretaria Acadêmica; Divisão de Planejamento e Gestão; e Divisão de Ensino e Avaliação. Estes setores administrativos, atualmente, funcionam em outro espaço físico do Campus, denominado "Prédio Administrativo e Gabinete dos Professores". No espaço registrado na fotografia permanecem a Divisão de Pesquisa e Pós-Graduação e o Diretório Acadêmico.

Os blocos de sala de aula, o acesso a esses blocos e a outros espaços do Campus também já foram modificados. Nas fotografias, abaixo, encontramos a passarela de acesso ao bloco de salas de aula do Curso de Letras e a via principal de acesso ao Campus, em dois momentos distintos:

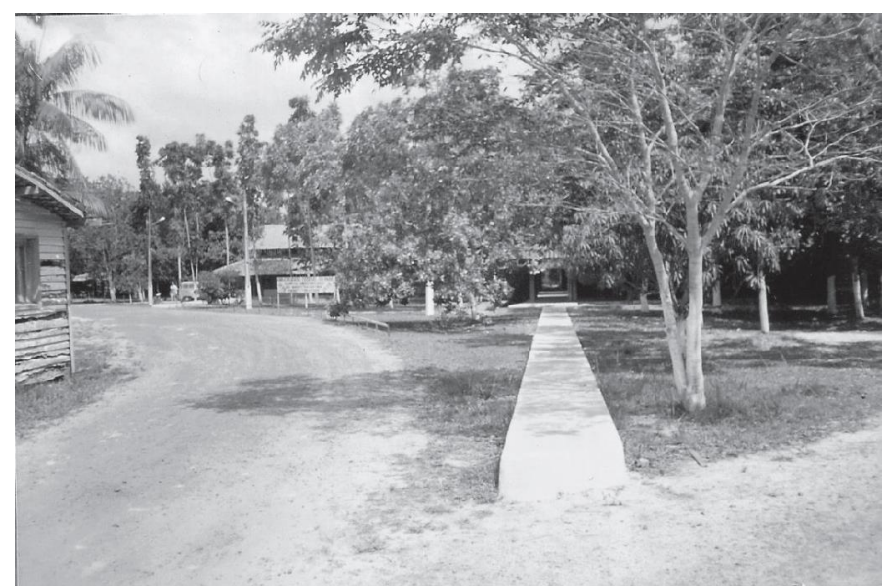

Fotografia 05: Passarela de acesso ao bloco de salas de aula do Curso de Letras.

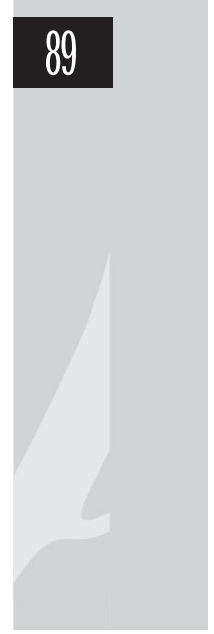




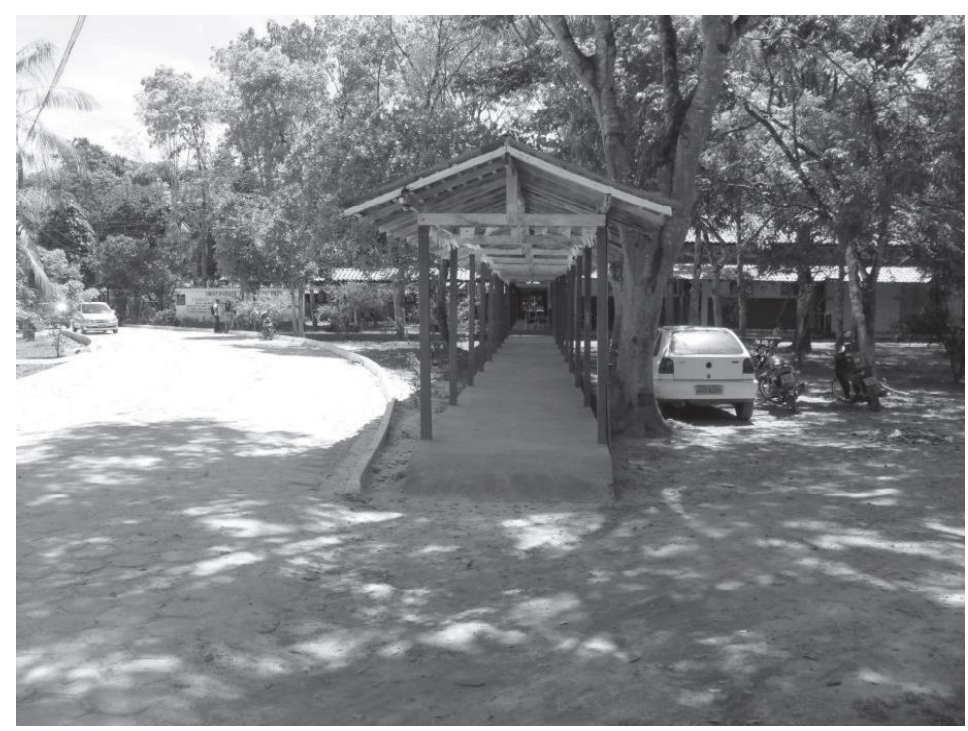

Fotografia 06: Passarela de acesso ao bloco de sala de aula do Curso de Letras.

A passarela, reta, no centro da imagem, registra uma das entradas principais de acesso ao Campus. Esta passarela conduz para as salas de aula do Curso de Letras, as quais estão localizadas logo à frente, à direita; além de outros espaços, tais como, o Bloco das Faculdades do Campus, à esquerda; e o bloco, à direita, dos Laboratórios de Informática. À esquerda de quem observa as imagens identificamos a via principal de entrada, curvada à esquerda, a qual passa pelo atual espaço “Toca-Tocantins”, na fotografia 02, e termina na Caixa D'água do Campus. As fotografias, portanto, tiradas de mesmo ângulo, apontam para mudanças efetivas na estrutura física do Campus. Ressaltamos a passarela coberta e a substituição da via principal de terra por blockets de concreto.

Para encerrar a análise das fotografias, achamos interessante trazer à tona, o atual cartão-postal do Campus. A fotografia 07, abaixo, evidencia mudanças físicas e aponta para outras questões que se faz necessário ir além da imagem para que seja possível registrá-las. 


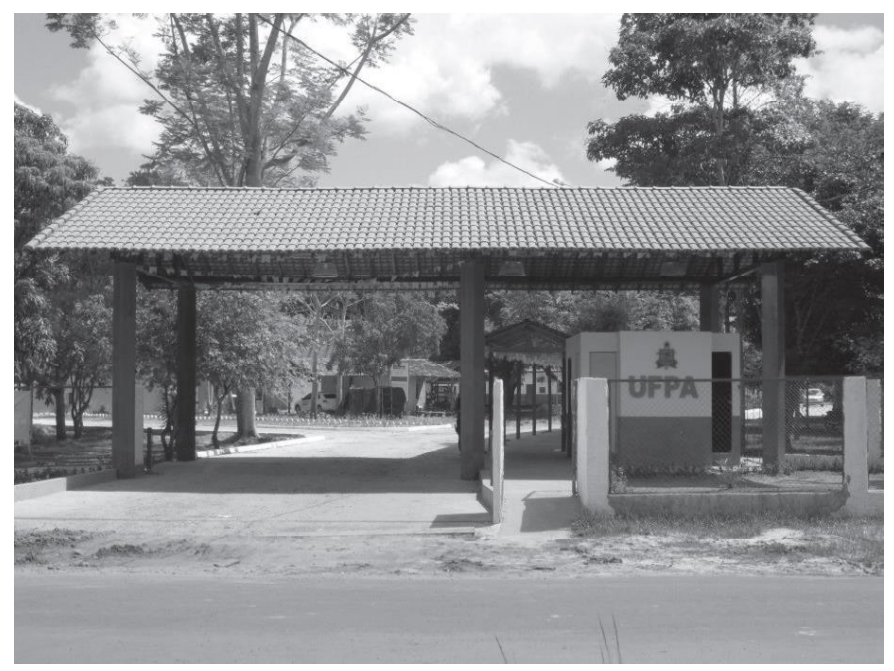

Fotografia 07: Atual portão de acesso ao Campus.

Percebemos, nesta fotografia, área verde menor do que aquela apresentada na Figura 01, deste artigo. É o indício de que, por trás daquele portão de entrada, ocorreram muitas mudanças no que diz respeito ao espaço físico, assim como no cotidiano das pessoas, em especial, devido a expansão dos Cursos.

Quanto ao espaço físico, o Campus de Abaetetuba comporta, atualmente, 9 prédios: o prédio das salas de aula da Faculdade de Ciências Exatas; Faculdade de Educação e Ciências Sociais; e Faculdade de Ciências da Linguagem; o prédio administrativo das Faculdades; o prédio que comporta os Laboratórios de Informática; o prédio "Toca Tocantins"; o prédio da Biblioteca e Auditório; o prédio do Laboratório de Linguagem; e o prédio Administrativo com os Gabinetes dos Professores.

O cotidiano das pessoas também foi influenciado pela expansão física e isto é notadamente visível por meio do fluxo de pessoas no Campus e as atividades diversas realizadas por estas. Atualmente, o Campus oferece cursos regulares de Licenciatura em Letras/Língua Portuguesa, Letras/ Língua Espanhola, Matemática, Pedagogia, Educação do Campo, Física, Bacharelado em Engenharia Industrial e Serviço Social. Oferta, também, através do Plano Nacional de Formação Docente/PARFOR, onze cursos de Licenciatura, a saber: Letras/Língua Portuguesa, Letras/Língua Espanhola, Letras/Língua Inglesa, Matemática, Pedagogia, História, 
Geografia, Sociologia, Ciências Naturais, Educação Física e Educação do Campo, todos ofertados na Escola Estadual Benvinda de Araújo Pontes. Mais de 1.500 alunos, entre os cursos extensivos e intensivos, são matriculados no Campus de Abaetetuba, o qual está flexibilizando seus cursos para os municípios vizinhos. Projetos futuros também prometem influenciar o modo de vida de várias pessoas, entre eles, planos para a oferta de novos cursos em nível de Graduação e Pós-Graduação.

Quanto a pessoal, o Campus conta, atualmente, com 56 (cinquenta e seis) docentes do ensino superior e 19 (dezenove) técnico-administrativos em educação, entre estes, ocupantes de cargos nunca antes existentes no Campus de Abaetetuba, tais como: Técnico em Assuntos Educacionais, Administrador, Contador, Analista de Informação, Técnico em Laboratório de Informática e Física. De certo, a ampliação dos cursos e do espaço ainda aponta para a necessidade de mais servidores, quanto aos Técnico-Administrativos, por exemplo, é demasiado recente a lotação de um Assistente em Administração em cada uma das Faculdades e em outros setores do Campus, tais como, Divisão de Pesquisa e Pós-Graduação. Na Biblioteca, ainda é visível a necessidade de servidores, principalmente com a inauguração do novo prédio. Isto aponta para um avanço no número de servidores que ainda é insuficiente para corresponder as atuais necessidades do Campus.

Assim, percebemos que a expansão do Campus Universitário de Abaetetuba, no seu espaço geográfico, situado à Rua Manoel de Abreu, sem número, no Bairro do Mutirão, é uma história construída no tempo e por meio dos momentos vivenciados por seus sujeitos sociais. Percebemos, no decorrer deste artigo, que a expansão física do Campus está, paralelamente, relacionada à expansão dos Cursos. É nesta expansão dos Cursos e, consequentemente, na ampliação no número de alunos, servidores e colaboradores que encontramos a principal influência do Campus Universitário de Abaetetuba na vida das pessoas. Desta forma, temos uma história que extrapola o espaço geográfico quando analisamos a influência do Campus na formação dos alunos, na movimentação do mercado de trabalho, no desenvolvimento do Município, nas atividades de ensino, no incentivo à pesquisa e nos trabalhos de extensão oferecido à comunidade. É uma história que, dentro de uma história maior, a história da Universidade Federal do Pará; é construída sob as especificidades da 
região, sob os entremeios que movem a cultura local, as lendas, o modo de vida das pessoas, os costumes, e vem acompanhando as modificações ocorridas na sociedade.

\section{Considerações Finais}

Nesse entremeio histórico, no qual resgatamos os momentos específicos a que as imagens fotográficas fazem referência é que evidenciamos parte da memória do Campus Universitário de Abaetetuba. Por meio das imagens, objetivamos trazer à tona a memória da expansão do Campus Universitário de Abaetetuba e percebemos que essa expansão influencia cotidianamente a vida dos sujeitos envolvidos neste processo. Ressaltamos para a necessidade de se usar os registros fotográficos como instrumentos de guarda e preservação da memória, pois esses "contam" a história da instituição. Sua preservação é importante para que possamos compreender o presente, projetar o futuro, construir a identidade do grupo e levar o conhecimento às novas gerações. "Noutros termos, a memória é também identidade social e a fotografia documento basilar desta memória” (PINHEIRO; SOARES, 2011, p. 2).

Detemo-nos, neste artigo, à expansão física do Campus de Abaetetuba, por isso os registros fotográficos. No entanto, não devemos esquecer que essa expansão física acompanhou também a expansão dos cursos, do número de alunos e servidores. Recorremos ao registro da memória coletiva, enfatizando as imagens fotográficas, mas não podemos esquecer que existe uma memória individual e uma memória simbólica do Campus de Abaetetuba que precisa ser enfatizada: aquela que é contada e recontada pelos sujeitos que fizeram e ainda fazem parte desta história e, também, pelos sujeitos recentes nesta história que estão fazendo e ainda muito farão pelo desenvolvimento do Campus no Município de Abaetetuba.

Queremos dizer que: tão importante quanto guardar a memória coletiva de um grupo, é coletar e preservar a memória individual, deste mesmo grupo, pois a memória

"remete-se a fragmentos de lembranças individuais de modo a interiorizar (confrontar) a fotografia aos fatos tendo vistas a coletivizar o individualizado, estabelecendo uma relação 
com o tempo presente, uma vez que lembrar não é reviver, mas rever (revisitar com os olhos do presente) o passado para compreendê-lo" (PINHEIRO; SOARES, 2011, p. 2).

Isto significa que nossos esforços em preservar a memória do Campus de Abaetetuba, não devem parar por aqui, mas ir além, buscando as lacunas que deixamos, os feitos esquecidos, os desconhecidos, e alargarse à memória individual daqueles que tendo muito a dizer, ainda estão ocultados nesta história "traçada" no tempo. Não devemos esquecer que o "tempo é memória; [...] o tempo é o situar-se no passado e no presente. Tempo, memória e esquecimento. Uma trilogia para pensar a arte de lembrar, para estruturar um olhar sobre si, para revelar-se" (SOUZA; FORNARI, 2008, p. 114). Assim, a memória do Campus Universitário de Abaetetuba é escrita num tempo, um tempo simbólico e imaterial que se movimenta sobre as experiências dos sujeitos envolvidos e que busca um horizonte com perspectivas para uma Universidade da Amazônia Tocantina.

\section{REFERÊNCIAS}

EBERHARDT, Camila. Fotografias de escola: história, memória e representações sociais em escolas do município de torres durante o século XX. Conversas Interdisciplinares. Ano I, vol 1. Disponível: < revista. ulbratorres.com.br/site/images/anoI/artigo06.pdf> . Acesso: 05/07/2011.

Jornal Mundo Jovem. Fotografia, entre memória e documento. Disponível: $\quad$ www.mundojovem.com.br/artigo-fotografia-entrememoria-e-documento.php. Acesso: 05/07/2011.

94 KESSEL, Zilda. Memória e memória coletiva. Disponível: < www. museudapessoa.net/.../zilda_kessel_memoria_e_memoria_coletiva. pdf > . Acesso: 05/07/2011.

LE GOFF, Jacques. História e Memória. Trad. de Bernardo Leitão. Campinas: Editora da UNICAMP, 1990.

MOREIRA, Raimundo Nonato Pereira. História e Memória: Algumas observações. Disponível: < www.fja.edu.br/proj_acad/praxis/praxis 02/ documentos/ensaio 2.pdf > . Acesso: 05/07/2011. 
SILVA, Ligiane Aparecida da; LIMA, Rosilene de. Jacques Le Goff: estudo de conceitos em História da Educação. IX Congresso Nacional de Educação - EDUCERE. III Encontro Sul Brasileiro de Psicopedagogia. PUCPR, out, 2009.

SOUZA, Elizeu Clementino de; FORNARI, Liege Maria Sitja. Memória, (Auto) Biografia e Formação. In: VEIGA, Ilma Passos Alencastro; D’Ávila, Cristina Maria (Orgs.). Formação Docente: novos sentidos, novas perspectivas. São Paulo: Papirus, 2008.

UNIVERSIDADE MULTICAMPI. Abaetetuba. Disponível: $<$ http:// www3.ufpa.br/multi

$\underline{\text { campi/novo/index.php?option }=\text { com content } \& v i e w=\operatorname{article} \& \text { id }=235 \& \mathrm{I}}$ temid=184>.Acesso: 05/07/2011. 